\title{
Microencapsulation of a synbiotic into PLGA/alginate multiparticulate gels
}

\author{
Michael T. Cook ${ }^{a}$, George Tzortzis ${ }^{b}$, Dimitris Charalampopoulos ${ }^{c *}$, Vitaliy V. Khutoryanskiy ${ }^{a *}$ \\ ${ }^{a}$ School of Pharmacy, University of Reading, Reading, RG6 6AD, United Kingdom \\ ${ }^{b}$ Clasado Research Services Ltd, Science and Technology Centre, University of Reading, Earley \\ Gate, Whiteknights Road, Reading, RG6 6BZ, United Kingdom
}

${ }^{C}$ Department of Food and Nutritional Sciences, University of Reading, Reading, RG6 6AD, United Kingdom

*Corresponding authors at:

${ }_{11}$ Vitaliy Khutoryansky: School of Pharmacy, University of Reading, Reading, RG6 6AD, United

$12 \quad$ Kingdom

13 Dimitris Charalampopoulos: Food and Nutritional Sciences, University of Reading, Reading,

${ }_{14} \quad$ RG6 6AD, United Kingdom

$16 \quad$ E-mail: V.Khutoryanskiy@reading.ac.uk

$17 \quad$ Tel: $+44(0) 1183786119$

Keywords: prebiotic, probiotic, encapsulation, GOS, galacto-oligosaccharides, bifidobacterium. 


\section{${ }_{25}$ Abstract}

26

Probiotic bacteria have gained popularity as a defence against disorders of the bowel. However, the acid sensitivity of these cells results in a loss of viability during gastric passage and, consequently, a loss of efficacy. Probiotic treatment can be supplemented using 'prebiotics', which are carbohydrates fermented specifically by probiotic cells in the body. This combination of probiotic and prebiotic is termed a 'synbiotic'. Within this article a multiparticulate dosage form has been developed, consisting of poly(D,L-lactic-co-glycolic acid) (PLGA) microcapsules containing prebiotic Bimuno ${ }^{\mathrm{TM}}$ incorporated into an alginate-chitosan matrix containing probiotic Bifidobacterium breve. The aim of this multiparticulate was that, in vivo, the probiotic would be protected against gastric acid and the release of the prebiotic would occur in the distal colon. After microscopic investigation, this synbiotic multiparticulate was shown to control the release of the prebiotic during in vitro gastrointestinal transit, with the release of galacto-oligosaccharides (GOS) initially occurred over $6 \mathrm{~h}$, but with a triphasic release pattern giving further release over $288 \mathrm{~h}$. Encapsulation of $B$. breve in multiparticulates resulted in a survival of $8.0 \pm 0.3 \log \mathrm{CFU} / \mathrm{mL}$ cells in acid, an improvement over alginatechitosan microencapsulation of $1.4 \log \mathrm{CFU} / \mathrm{mL}$. This was attributed to increased hydrophobicity by the incorporation of PLGA particles.

Abbreviations: DCM, dichloromethane; FITC, fluorescein isothiocyanate; GI, gastrointestinal; GOS, galacto-oligosaccharides; IL-6, interleukin-6; PBS, phosphate-buffered saline; polydispersity index, PDI; PLGA, poly(D,L-lactic-co-glycolic acid); TNF- $\alpha$, tumor necrosis factor $\alpha$; WC, Wilkins-Chalgren 


\subsection{Introduction}

Probiotic bacteria have attracted interest due to their potential to alleviate some specific conditions of the bowel when administered orally (Rembacken et al., 1999). The intention of taking these cells orally is to modify the balance of the indigenous gut microflora in favour of strains which can exert some positive biological action (Fuller, 1991). These biological actions are numerous, and sometimes poorly understood. Examples of probiotic action include: the modulation of immune response, competition with pathogens and the production of antimicrobial compounds (Ng et al., 2009). Research suggests that these cells are most effective whilst live (or 'viable'), and passage through the stomach often results in cell death, lowering the efficacy of an administration. Thus, research has focused on methods to improve cell survival in the stomach, and, as a result, improve the efficacy of a probiotic (Cook et al., 2012). Commonly, microencapsulation, which involves the entrapment of the probiotic cells into polymeric materials, is used to achieve this aim. Research has traditionally focussed on the use of polysaccharides, such alginate (Chavarri et al., 2010; Cook et al., 2011; Cook et al., 2013; Mokarram et al., 2009), xanthan gum (Ding and Shah, 2009) and starch (Muthukumarasamy et al., 2006; Sultana et al., 2000), but there is an emerging trend towards the use of encapsulation in proteins, such as casein (Heidebach et al., 2009; Oliveira et al., 2007), whey protein (Doherty et al., 2012a; Doherty et al., 2012b; Doherty et al., 2010, 2011) and gelatin (Borza et al., 2010; Li et al., 2009).

An alternative approach to boost the number of probiotic cells in the intestine is by the consumption of a 'prebiotic'. These prebiotics are compounds which are specifically fermented by a probiotic in vivo, increasing the number of these cells present in the host (Gibson et al., 2004; Gibson and Roberfroid, 1995). One such prebiotic is BiMuno ${ }^{\mathrm{TM}}$, which is comprised of mostly galacto-oligosaccharides (GOS) with degrees of polymerisation (DP) of $2-4$, having $\beta$ 1$3, \beta 1-4$, and $\beta$ 1-6 linkages, and a disaccharide fraction of $\alpha$ 1-6 galactobiose (Tzortzis et al., 
2005). BiMuno ${ }^{\mathrm{TM}}$ has been shown to reduce colonisation of pathogenic Salmonella

Typhimurium in mice by Searle et al (Searle et al., 2009).The functional components of the BiMuno $^{\mathrm{TM}}$ mixture are the GOS which are believed not only to stimulate the growth of probiotic bacteria, but may also be able to interact directly with the subject's immune system. This latter possibility has been touted due to studies in murine BALB/c macrophage models showing up-regulation of cytokines related to immune response, specifically TNF- $\alpha$ and IL-6 (Searle et al., 2012). It has been shown by Tzorzis et al (Tzortzis et al., 2005) that BiMuno ${ }^{\text {TM }}$ had a bifidogenic effect in the colon of pigs, boosting number of Bifidobacterium spp by 0.74 $\log (\mathrm{CFU}) / \mathrm{mL}$ in the proximal colon, but by only $0.38 \log (\mathrm{CFU}) / \mathrm{mL}$ in the distal regions of the colon. It was postulated that this imbalance in growth may be caused by the fermentation of GOS by cells in the proximal region, reducing the concentration of the usable GOS further along the gut. A product containing both a pro- and pre- biotic is termed a 'synbiotic', and has been highlighted as a possible means of improving the efficacy of a probiotic supplement. It was the intention of the work herein to produce a microencapsulated synbiotic product containing GOS and a probiotic (Bifidobacterium breve), to impart protection to the encapsulated cells and to control the release of the prebiotic across the intestine, which can then act on the hosts indigenous microflora.

The production of an encapsulated synbiotic has several different challenges compared to the formulation of the probiotic alone. One particular advantage of encapsulating GOS, compared to probiotic cells, is that relatively harsh processing conditions during the encapsulation step may be used. However, for a synbiotic containing GOS and probiotic cells, careful consideration must be taken in order to ensure the applicability of the system to both bioactives. In order to improve the survival of cells through the stomach, probiotics have been microencapsulated into alginate polysaccharide gels, which have been modified by various methods (Chandramouli et al., 2004; Chavarri et al., 2010; Cook et al., 2012; Cui et al., 2007; 
Graff et al., 2008). It has been shown that coating alginate microcapsules with one or more layers of chitosan leads to an improvement in the survival of probiotic cells during exposure to acid (Chavarri et al., 2010; Cook et al., 2011; Doherty et al., 2012a; Liserre et al., 2007). It has also been demonstrated that the incorporation of other materials, such as starch, into the alginate matrix can affect the microcapsule properties (Homayouni et al., 2008; Sultana et al., 2000). In this paper, a multiparticulate microencapsulation system was devised to offer controlled release to GOS, and protection of B. breve to acid. This consisted of individually microencapsulated BiMuno ${ }^{\mathrm{TM}}$, which was then incorporated into a chitosan-coated alginate gel containing B. breve, a model probiotic strain. The GOS was encapsulated into a separate system which offers a time-dependent release of small molecules, as the alginate microencapsulation system is too porous to contain the GOS contained in BiMuno ${ }^{\mathrm{TM}}$.

Poly(D,L-Lactic-co-Glycolic acid) (PLGA) was identified as a plausible material for the timedependent release of GOS. PLGA was chosen as an encapsulating material as it is highly biocompatible, FDA-approved, and has been shown to control the release of water-soluble drugs, extending their delivery from hours (Wischke and Schwendeman, 2008) up to months (Corrigan and Li, 2009). The biodegradation process occurs simply in solution by hydrolysis of the ester linkages between the monomers. This results in the breakdown of the polymer chains into lactic and glycolic acid, both of which are easily metabolised in the body.

There have been a number of multiparticulate dosage forms reported in the literature for the targeting of drugs to the intestine. Eudragit-coated PLGA particles containing budesonide have been fabricated by Krishnamachari et al (Krishnamachari et al., 2007). These particles were intended to deliver the encapsulated drug to the colon, and showed impressive steady release of drug over 25 hours. There has also been a study of alginate-PLGA multiparticulates for the delivery of silymarin (El-Sherbiny et al., 2011). These delivery devices consisted of PLGA nanoparticles, produced through a single emulsion solvent evaporation technique, which were 
incorporated into alginate matrices through the conventional ionotropic gelation method. In vitro GI release studies found that approximately $80 \%$ of encapsulated silymarin was delivered over around 10 hours. The release was $\mathrm{pH}$ dependent, with a clear targeting of delivery to simulated intestinal solution. After the change of $\mathrm{pH}$ there was a release of up to $50 \%$ of silymarin over the course of 2 hours.

It should be noted that diarrhoea is common in bowel disorders, which may lead to premature clearing of microparticles. It has been found that clearing due to diarrhoea is sizedependent and that particles of less than 200 microns are retained more effectively during diarrhoea, thus, it is important that microparticles are produced with diameters lower than this threshold (Lamprecht et al., 2004).

This work aimed to develop a multiparticulate system to encapsulate a synbiotic combination of GOS and B.breve. The development of PLGA-GOS microcapsules will be discussed, followed by characterisation of particle size and morphology using microscopy. The release of GOS from these particles in simulated GI conditions was then evaluated and the system expanded to a multiparticulate containing probiotic cells, with associated cell and GOS release data.

\subsection{Materials and methods}

\subsection{Materials}

Sodium alginate (19-40 kDa, M:G ratio $3.3 \pm 0.3$ (Wright et al., 2012)), low molecular-weight chitosan (103 kDa, degree of deacetylation: $85.6 \%$ ) and fluorescein isothiocyanate (FITC) were purchased from Sigma-Aldrich (Gillingham, U.K.). Bifidobacterium breve NCIMB 8807 was purchased from the National Collection of Industrial Food and Marine Bacteria (Aberdeen, U.K.). Wilkins-Chalgren (WC) anaerobe agar and phosphate-buffered saline (PBS) were purchased from Oxoid (UK). PLGA 5002A was purchased from PURAC (Gorinchem, Netherlands). This grade of PLGA was chosen as it had a relatively quick time for complete 
biodegradation, 0.5-1 month(s). The manufacturer's guide gave an Mw of $17 \mathrm{kDa}$.

Dichloromethane (DCM) was purchased from Sigma-Aldrich (U.K.). BiMuno ${ }^{\mathrm{TM}}$ was provided by Clasado Research Services Ltd (Reading, U.K.) as a $68 \%(\mathrm{w} / \mathrm{v})$ aqueous syrup. Simulated gastrointestinal (GI) solutions were made according to the United States Pharmacopeia, without enzymes. Adjustments to $\mathrm{pH}$ are shown in brackets after solution name. Chitosan solutions were at $0.4 \% \mathrm{w} / \mathrm{v}$ in $0.1 \mathrm{M}$ acetic acid and the $\mathrm{pH}$ adjusted to $\mathrm{pH} 6.0$ with $1 \mathrm{M} \mathrm{NaOH}$.

\subsection{Production of PLGA microcapsules containing GOS}

The microencapsulation of GOS was attempted by a solvent evaporation technique (Herrmann and Bodmeier, 1995). To form the WOW emulsion, $0.5 \mathrm{~mL}$ aqueous BiMuno ${ }^{\mathrm{TM}}$ solution of a known concentration was added to $10 \mathrm{~mL}$ PLGA solution (10\% w/v) in DCM with overhead stirring at $1200 \mathrm{rpm}$ for $60 \mathrm{~s}$. This primary emulsion was then transferred into $100 \mathrm{~mL}$ aqueous alginate solution $(1 \% \mathrm{w} / \mathrm{v})$ with overhead stirring at $1200 \mathrm{rpm}$, resulting in the formation of a secondary WOW emulsion. The WOW emulsion was then left to stir at room temperature for 60 min which allowed the evaporation of DCM. After 60 min of stirring, microcapsules were collected via centrifugation at 1,000 rpm for $10 \mathrm{~min}$, twice washed with $50 \mathrm{~mL}$ deionised water and freeze-dried (Thermo LL3000) to allow removal of water from the discrete phase. Samples were then stored in a desiccator before use. Scanning electron microscopy (SEM) was performed on the samples to examine their structure. The initial experiment conducted was simply to establish the relationship between particle size and the concentration of BiMuno ${ }^{\mathrm{TM}}$ used. BiMuno ${ }^{\mathrm{TM}}$ solutions of 10,20 and $30 \%(\mathrm{w} / \mathrm{v})$ were prepared and used as the internal water phase in the procedure above. The particles produced were then sized by observation on a light microscope (Leica DM2500). The diameter of 100 particles was measured using ImageJ.

\subsubsection{Release of GOS from PLGA microcapsule in in vitro GI solutions}




\subsubsection{Ion-exchange HPLC of BiMuno ${ }^{T M}$}

BiMuno's GOS components were analysed by ion-exchange HPLC. In order to quantify GOS in the following release experiments, a Rezex RCM-monosaccharide column (Phenomenex, U.K.) was used, running HPLC-grade water at a flow rate of $0.5 \mathrm{~mL} / \mathrm{min}$ with an oven temperature of $85^{\circ} \mathrm{C}$ (Fig 1s, Supporting information). However, this HPLC technique was very sensitive to salts, especially phosphates, present in the Gl solutions. The salts were removed from solution using an amino-column running $60 \% \mathrm{v} / \mathrm{v}$ acetonitrile in water at a flow rate of $1 \mathrm{~mL} / \mathrm{min}$ with an oven temperature of $30^{\circ} \mathrm{C}$. The GOS peak could then be separated from phosphate salts using a fraction collector and the solvent removed from solution by heating in an oil bath (50 ${ }^{\circ} \mathrm{C}$, until complete evaporation). The resulting residue was dissolved in a volume of pure water equal to that injected $(200 \mu \mathrm{L})$ and was analysed once more by the ion-exchange method. This method led to a significant ( $52.9 \pm 2.6 \%$ ), but reproducible loss of GOS, which could be corrected for during determination of GOS concentration in simulated GI solutions. It should also be clarified that when describing the data from these release experiments the GOS concentration is given as a percentage of the theoretical maximum GOS content assuming 100 $\%$ encapsulation efficiency.

\subsubsection{Quantification of GOS release in simulated GI solutions}

GOS-containing PLGA microcapsules were produced as above and re-suspended in $10 \mathrm{~mL}$ simulated gastric solution (at $\mathrm{pH} 2.0$ ). This solution was then incubated at $37^{\circ} \mathrm{C}$ with shaking at $100 \mathrm{rpm}$ for $60 \mathrm{~min}$. A sample was then taken through a syringe and microfilter to ensure that no microcapsules were drawn into the syringe. The particles in solution were then centrifuged at $1,000 \mathrm{rpm}$ for $10 \mathrm{~min}$, the simulated gastric solution removed and the particles resuspended in $50 \mathrm{~mL}$ simulated intestinal solution $(\mathrm{pH} 6.0)$ to simulate entry to the small intestine, and incubated as before. After $60 \mathrm{~min}$ of incubation a sample was taken and the particles in solution centrifuged, the supernatant removed and the resulting pellet re- 
suspended in $50 \mathrm{~mL}$ simulated intestinal solution $(\mathrm{pH} 7.2)$ to simulate the $\mathrm{pH}$ of the distal small intestine, and incubated. After $120 \mathrm{~min}$ at this $\mathrm{pH}$ a sample was taken. This two stage process was attempting to approximate the $\mathrm{pH}$, temperature and duration of small intestinal passage, following gastric passage. The microcapsules were then removed from solution by centrifugation and re-suspended in $50 \mathrm{~mL}$ simulated intestinal solution $(\mathrm{pH} \mathrm{5.5),} \mathrm{which}$ intended to simulate the $\mathrm{pH}$ of the proximal colon. Samples $(2 \mathrm{~mL})$ were then taken at numerous time points for up to 12 days. After each sample was taken, an equivalent volume of simulated $\mathrm{Gl}$ solution $(2 \mathrm{~mL}$ ) was added to replace that loss. An overview of this simulated GI passage is shown in the supplementary information (Fig. 2s).

\subsection{Effect of discrete aqueous phase volume on release rate of GOS from PLGA microcapsules} PLGA microcapsules containing GOS were prepared as before, but with $0.5,1.0$ and $2.0 \mathrm{~mL}$ BiMuno $^{\mathrm{TM}}$ solution $(20 \% \mathrm{w} / \mathrm{v})$ added during the formation of the primary emulsion. These microcapsules were then put through the simulated GI passage described previously. The encapsulation efficiency of the $1.0 \mathrm{~mL}$ internal phase microcapsules was estimated by the measurement of GOS in the continuous alginate phase.

\subsubsection{Release of GOS from alginate and alginate-chitosan microcapsules} In order to evaluate the effect of alginate microencapsulation on the release of GOS, an in vitro GI passage was used. A solution containing $2 \% \mathrm{w} / \mathrm{v} \mathrm{BiMuno}^{\mathrm{TM}}$ and $2 \% \mathrm{w} / \mathrm{v}$ alginate was prepared. $1 \mathrm{~mL}$ of this solution was extruded with a syringe and pump ( $2 \mathrm{~mL} / \mathrm{min})$ into $50 \mathrm{~mL}$ $\mathrm{CaCl}_{2}$ solution $(0.05 \mathrm{M})$ and left to harden for $30 \mathrm{~min}$. Then, in the case of chitosan-coated capsules, the hardened sample was placed into chitosan solution for 10 min to allow coating of the samples. The capsules were then dried by fluid-bed drying for $15 \mathrm{~min}$ at $30^{\circ} \mathrm{C}$, with an 
airflow at $50 \%$ power. To evaluate the release of GOS from these particles, the in vitro GI passage previously described was used. However, the study was halted before the final section $(\mathrm{pH} 5.5)$ due to the complete dissolution of the microcapsules.

\subsubsection{Purification of GOS samples revisited}

Due to the incompatibility of alginate with the eluent in the purification procedure used previously, a new purification procedure was used for the experiments involving alginate. Samples $(10 \mathrm{~mL})$ were adjusted to $\mathrm{pH} 7-7.5$, with a measured volume of $\mathrm{NaOH}(1 \mathrm{M})$. To these samples $10 \mathrm{~mL} \mathrm{CaCl}(0.05 \mathrm{M})$ was added, at which point the solutions became cloudy due to the formation of insoluble calcium phosphate and calcium-alginate. The solution could then be microfiltered ( $0.45 \mu \mathrm{m}$ filter), removing the phosphates and alginate present. These samples could then be analysed by ion-exchange HPLC. This method was validated before use by the purification of a known concentration of BiMuno ${ }^{\mathrm{TM}}$, giving full recovery of GOS.

2.6 Release of GOS from alginate and alginate-chitosan encapsulated PLGA multiparticulates The previously evaluated GOS/PLGA microcapsules were prepared as before and placed into $10 \mathrm{~mL}$ alginate solution $\left(2 \% \mathrm{w} / \mathrm{v}\right.$ ) with stirring before extrusion into $500 \mathrm{~mL} \mathrm{CaCl}{ }_{2}$ solution $(0.05 \mathrm{M})$ with a syringe and pump $(2 \mathrm{~mL} / \mathrm{min})$. These multiparticulate capsules were allowed to harden for $30 \mathrm{~min}$ and, in the case of chitosan-coated capsules, placed in $0.4 \% \mathrm{w} / \mathrm{v}$ chitosan solution for $10 \mathrm{~min}$. The capsules were then dried by fluid-bed drying as before. Fluid-bed dried microcapsules were stored in a desiccator until use. These multiparticulates were then run through the same in vitro GI transit model used for the GOS/PLGA microcapsules, shortened to $72 \mathrm{~h}$, due to the likelihood of excretion in vivo by this point. Additionally, due to the larger sample size, volumes of simulated GI solutions used were multiplied ten-fold. 
Samples $(10 \mathrm{~mL})$ were collected as previously described and taken for purification before analysis.

\subsection{Viability and release of $B$. breve encapsulated in synbiotic microcapsules} To determine whether the final prebiotic system would also allow the survival of cells, an in vitro test was conducted. B. breve was grown at $37^{\circ} \mathrm{C}$ for $72 \mathrm{~h}$, anaerobically on WC anaerobe agar before inoculation into $10 \mathrm{~mL}$ TPY broth. The inoculated cell suspension was grown at 37 ${ }^{\circ} \mathrm{C}$ for $22 \mathrm{~h}$, before centrifugation at $3200 \mathrm{rpm}$ for $15 \mathrm{~min}$ at $4{ }^{\circ} \mathrm{C}$. The supernatant was removed and the cell pellet re-suspended in sufficient $2 \% \mathrm{w} / \mathrm{v}$ microfiltered alginate solution to $\mathrm{OD}_{600} \sim 2.0$. To $10 \mathrm{~mL}$ of this polymer/cell solution, PLGA microcapsules containing GOS were added, produced with $1 \mathrm{~mL}$ internal phase as previously described, with stirring. This solution was extruded using a syringe and pump (flow rate $2.0 \mathrm{~mL} / \mathrm{min}$ ) into $50 \mathrm{~mL} \mathrm{CaCl}(0.05 \mathrm{M})$ and left in solution to harden for 30 min. Microcapsules were then coated with 1 layer of chitosan as described in a previous publication (Doherty et al., 2012a). These synbiotic multiparticulates were then dried by fluid-bed drying for $15 \mathrm{~min}$ at $30{ }^{\circ} \mathrm{C}$, and airflow at $50 \%$ of full power. The microcapsules were then put through the simulated GI transit described previously. Samples taken were assessed for live cell content by plate counts on WC agar. This gave a representation of the numbers of cells surviving in the low $\mathrm{pH}$ gastric solution and the rate of release of these cells.

\subsection{Scanning electron microscopy}

SEM was performed on samples throughout various stages of this article. Typically, samples were prepared for SEM by drying, followed by adhesion to a carbon stub and sputter coating with gold. SEM was performed on an FEI Quanta 600 FEG environmental SEM under high- 
vacuum and using a point size of 3 . The images presented in Fig.1 used a $5.0 \mathrm{kV}$ electron beam, all other images were taken using a $20 \mathrm{kV}$ electron beam.

\subsection{Statistical analysis}

Where used, statistical significance was determined by one-way ANOVA with Tukey's post-hoc test using Graphpad Prism (USA).

\subsection{Results and discussion}

\subsection{Production and sizing of PLGA microcapsules}

The production of PLGA microcapsules containing GOS was achieved using a solvent evaporation technique based on the modification of known methods (Herrmann and Bodmeier, 1995). Observation of these microcapsules using SEM revealed that the microcapsules were spherical with a smooth surface (Figure 1). The sample appears relatively polydisperse, and any damaged capsules showed that the microcapsules were hollow with a dense crust with a thickness of approximately $1 \mu \mathrm{m}$ (measured by ImageJ). 


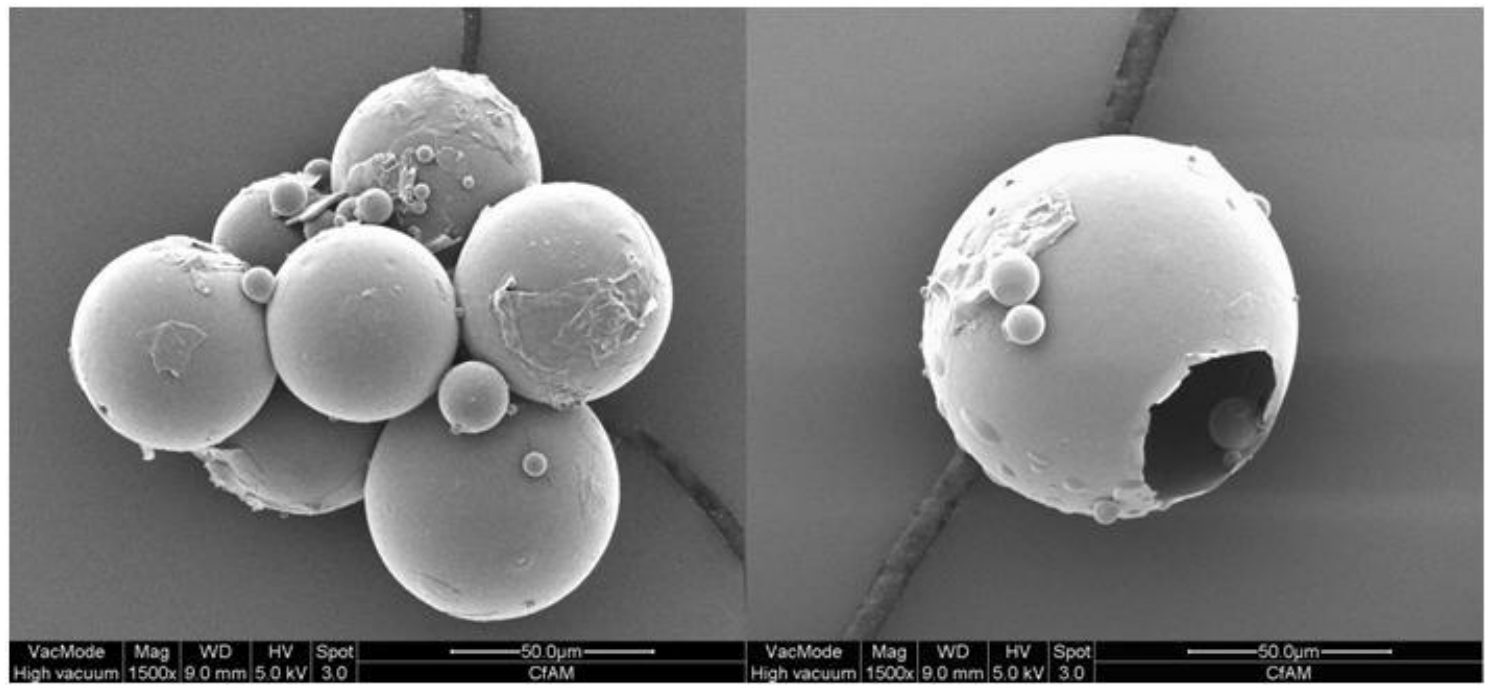

Figure 1: SEM images of PLGA microcapsules containing GOS. Please note that the damage seen on the right image is atypical for this sample, and was chosen to demonstrate that the capsules were hollow.

The effect of BiMuno ${ }^{\mathrm{TM}}$ concentration on the average particle size and distribution was determined by light microscopy and subsequent image analysis using ImageJ. This data, shown in Table 1, is represented as the mean diameter and polydispersity index (PDI) of three separate batches of microcapsules. The PDI is defined as:

$$
\mathrm{PDI}=(\text { standard deviation } / \text { mean })^{2}
$$

It is clear from this experiment that increasing the concentration of BiMuno ${ }^{\mathrm{TM}}$ from 10 to $20 \%$ $(w / v)$ resulted in a greater than two-fold decrease in the particle diameter. Increasing the concentration to $30 \%(\mathrm{w} / \mathrm{v})$ did not have a significant effect on the particle diameter. There was no significant difference in the polydispersity of the particles between conditions. The polydispersity of the sample could have consequences on the release rate of GOS from these particles. The release rate should be dependent in part on the size of the microcapsules (Klose et al., 2006), so it is important to attempt to make the particle size as regular as possible. As 
there was no difference between the 20 and $30 \%$ GOS samples, $20 \%$ GOS was taken on for further experimentation. It should be noted that the concentration of GOS in the internal phase may affect the encapsulation efficiency of the system (Mao et al, 2007), and may be a factor which could be optimised in terms of encapsulation efficiency, as well as particle size.

Table 1: Effect of GOS concentration on PLGA particle size and PDI. Data given as mean \pm standard deviation $(n=3)$. Superscript letters separate values which are significantly different $(p<0.05)$.

\begin{tabular}{|l|l|l|}
\hline $\begin{array}{l}\text { BiMuno } \\
\text { phase }(\%)\end{array}$ & Particle diameter $(\mu \mathrm{m})$ & PDI \\
\hline 10 & $97.3 \pm 9.1^{\mathrm{a}}$ & $0.6 \pm 0.1^{\mathrm{c}}$ \\
\hline 20 & $45.2 \pm 5.3^{\mathrm{b}}$ & $0.4 \pm 0.1^{\mathrm{c}}$ \\
\hline 30 & $44.8 \pm 3.7^{\mathrm{b}}$ & $0.5 \pm 0.1^{\mathrm{c}}$ \\
\hline
\end{tabular}

\subsection{Release of GOS from PLGA microcapsules during exposure to simulated GI solutions}

The release of GOS from these GOS/PLGA microcapsules under in vitro $\mathrm{GI}$ conditions was measured by ion-exchange HPLC. These studies were initially conducted over a lengthy time period, to understand the full release profile of PLGA microcapsules containing GOS. 12 days incubation in simulated intestinal solution gave a triphasic release profile (Figure 2). The initial phase of release (0-6 h) was likely caused by the diffusion of GOS through pores or the polymer itself. This was followed by a second phase of very little release (6-24 h) at which point the GOS able to diffuse had diminished and the PLGA chains were slowly hydrolysing. The third phase of release (24-288 $\mathrm{h}$ ) was the result of the erosion of the particles as the molecular weight of PLGA reduced to such a degree that it became water-soluble. This triphasic release profile predicts that around $25 \%$ of GOS (19 mg GOS/g particles) should be released after $6 \mathrm{~h}$ intestinal transit. This transit time should cover gastric and small intestinal transit (approximately $4.5 \mathrm{~h}$ ) and the beginnings of large intestinal passage. The second phase 

Phase: 1

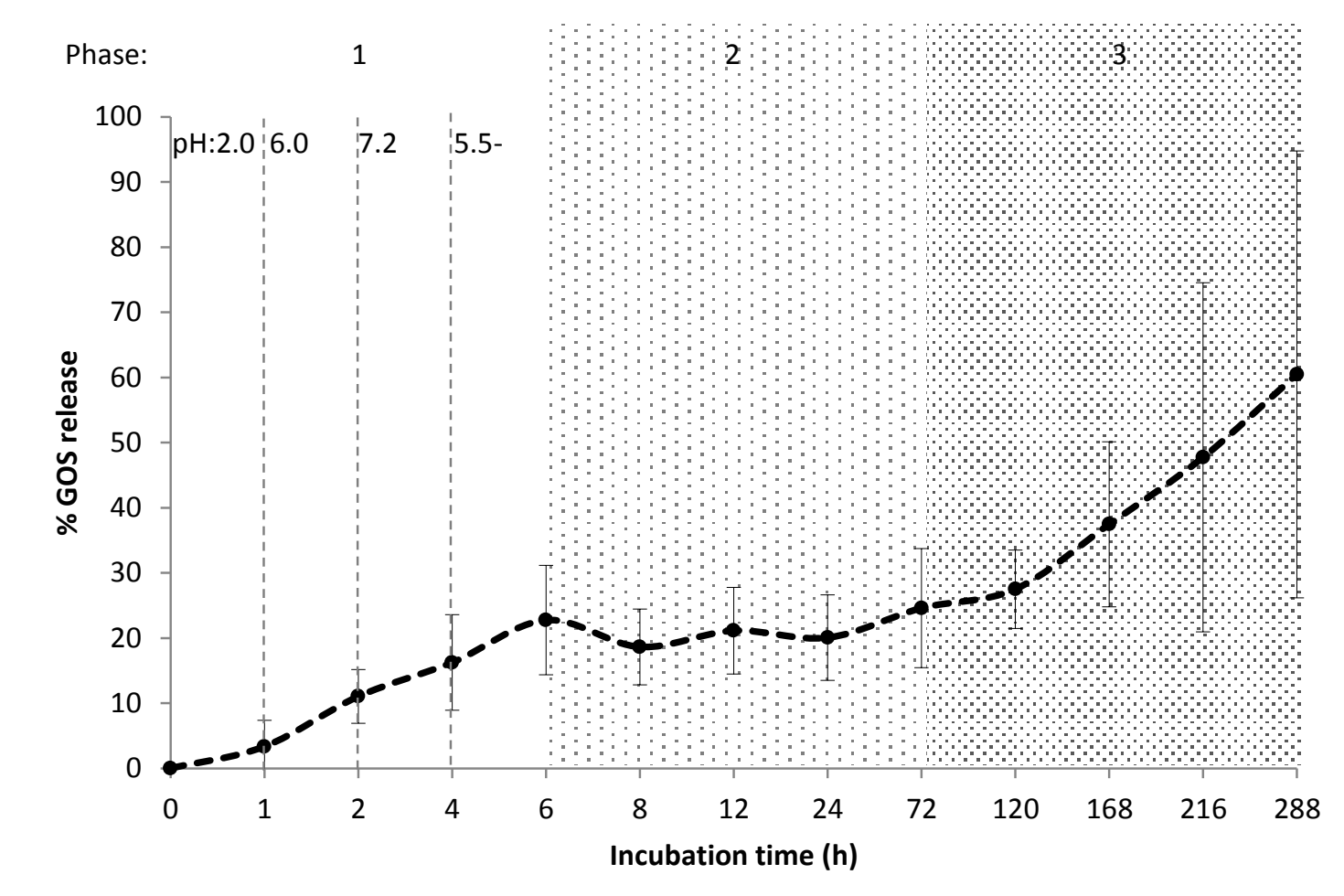

of release should occur during the remainder of large intestinal transit, however, very little GOS release occurs during this time. The third phase of release would not be reached in the body unless the PLGA particles were very effectively retained after accumulation in ulcers, as has been reported for PLGA microcapsules (Schmidt et al., 2013). This triphasic release profile has been reported by other groups working on hollow PLGA particles (Cohen et al., 1991; Sturesson et al., 1993).

Figure 2: Release of GOS from PLGA microparticles, expressed as a percentage of GOS initially added to emulsion. Results given as mean \pm standard deviation $(n=4)$. Please note that the $x-$ axis is not linear.

3.3 Effect of internal phase volume on the porosity and release of GOS from PLGA microcapsules 
After the initial study, attempts were made to increase the rate of release of GOS from these materials in order to try and recover greater amounts of GOS from these devices during GI passage. Work conducted by Schlicher et al (Schlicher et al., 1997) and Mahboubian et al (Mahboubian et al., 2010) found that increasing the volume of the internal phase in WOW prepared PLGA microcapsules with increased their apparent surface porosity. It is believed that this increase in surface porosity results in an increased rate of drug release from the microcapsules. The internal phase volume was increased from $0.5 \mathrm{~mL}$ to 1.0 and $2.0 \mathrm{~mL}$, and the microcapsules' apparent porosity was examined using SEM (Figure 3), revealing a great increase in porosity as the internal phase volume was increased to $2.0 \mathrm{~mL}$. This was consistent with the literature available and was attributed to the increased probability of finding droplets of internal phase close to the boundary of the capsules during the microcapsule formation process (Herrmann and Bodmeier, 1995). This work by Herrmann and Bodmeier (Herrmann and Bodmeier, 1995) also raises the possibility of the thinning of the PLGA crust in higher internal phase volume microcapsules due to the initial enlargement of emulsion droplets. 


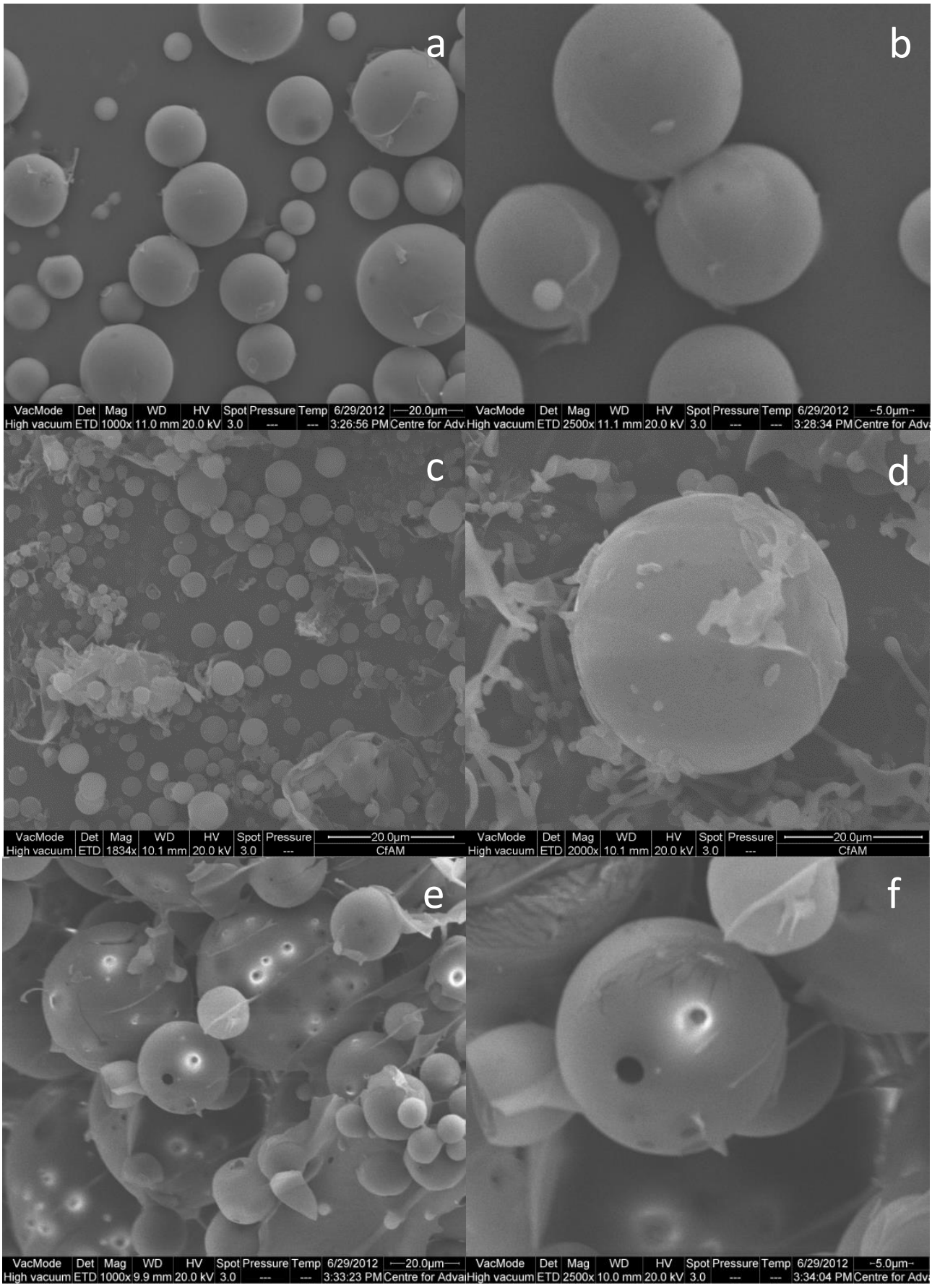

Figure 3: SEM images showing the morphology of microcapsules prepared with $0.5 \mathrm{~mL}(\mathrm{a}, \mathrm{b})$,

$1.0 \mathrm{~mL}(\mathrm{c}, \mathrm{d})$ and $2.0 \mathrm{~mL}(\mathrm{e}, \mathrm{f})$ internal phase volume (top to bottom).

In vitro $\mathrm{GI}$ transit was conducted with the microcapsules prepared with 1.0 and $2.0 \mathrm{~mL}$ internal 
a change in the release profile. These experiments (Figure 4) reveal that increasing the internal phase from 0.5 to $1.0 \mathrm{~mL}$ led to a slight increase in the percentage of GOS released over the first 6 hours of testing, from $24.40 \pm 5.21 \%$ to $36.11 \pm 2.33 \%$ (the latter correlating to $55.00 \pm$ $3.52 \mathrm{mg} \mathrm{GOS} / \mathrm{g}$ particles). This time period corresponds to the first phase of release outlined above and theoretically corresponds to stomach and small intestine transit time, and a portion of the distal colon. Increasing the internal phase volume further resulted in a very large reduction in the amount of GOS released during this phase, with only $10.30 \pm 1.13 \%$ GOS released. As this release does not take into account the encapsulation efficiency of the system, this data is also a reflection of the encapsulation efficiency of the system. The high porosity of the microcapsules seen in Fig 3e and $\mathrm{f}$ has presumably lead to a low encapsulation efficiency of the GOS in this case, which is reflected in the low concentration seen in the release data. The microcapsules containing $1.0 \mathrm{~mL}$ internal phase were taken forward for further analysis due to the slightly improved release profile and higher loading obtained. Direct measurement of the encapsulation efficiencies of the microencapsulation system was challenging, so, the data has been presented as the percentage of GOS released, relative to that put into the system. The encapsulation efficiency of the $1.0 \mathrm{~mL}$ system was estimated to be $90 \%$ by measuring the GOS present in the continuous alginate phase, i.e. the GOS not encapsulated into the microparticles. The encapsulation efficiency was calculated using the formula: encapsulation efficiency $=100-100$ (GOS present in continuous phase/quantity of GOS added). 


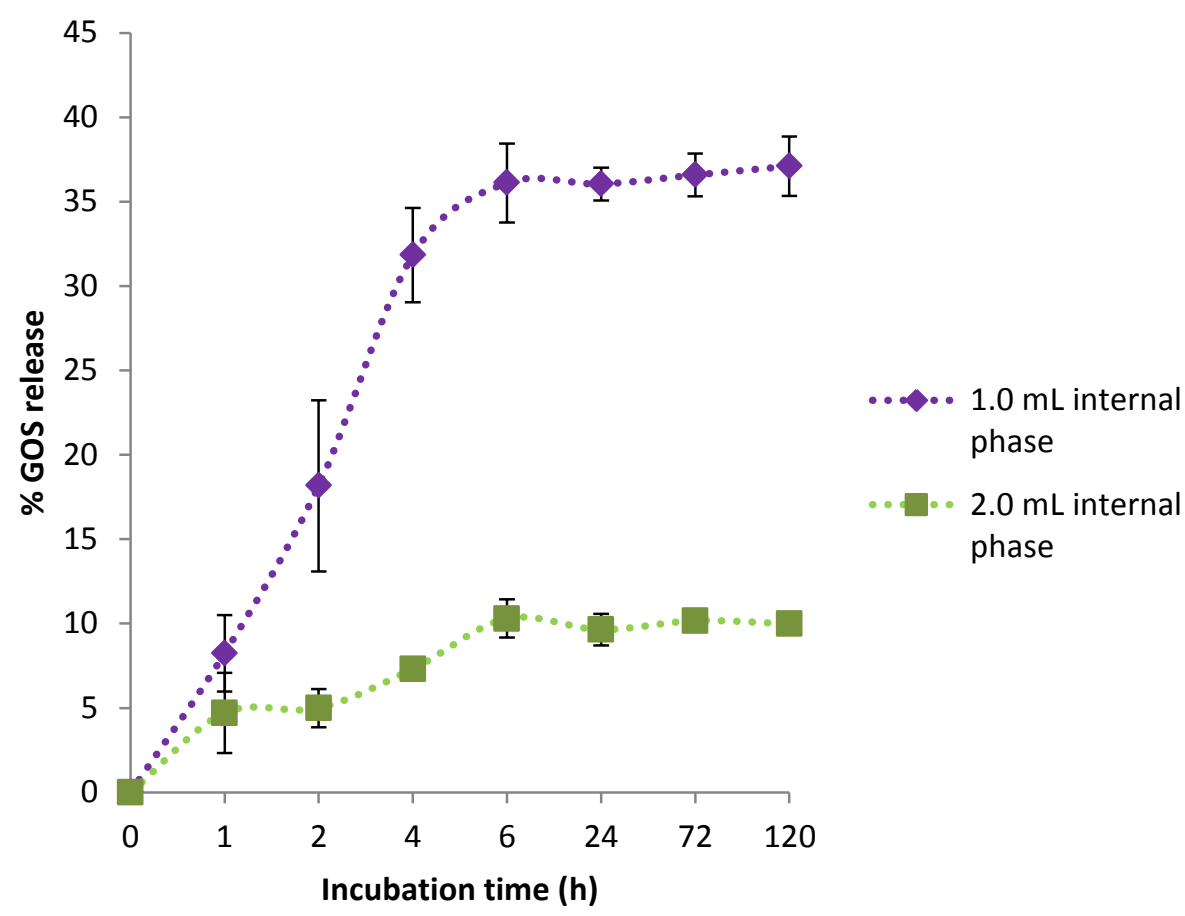

Figure 4: Effect of internal phase volume on the release of GOS from GOS/PLGA microcapsules. Data given as mean and standard deviation $(n=3)$. The position in the $\mathrm{Gl}$ tract simulated is overlayed. Please note that the $\mathrm{x}$-axis is not linear.

\subsection{Production and evaluation of PLGA/alginate multiparticulates}

The next step in the production of the intended synbiotic microcapsules was the incorporation of the $1.0 \mathrm{~mL}$ internal phase PLGA microcapsules into alginate gels. This can be simply achieved by the co-extrusion of alginate and the PLGA microcapsules into $\mathrm{CaCl}_{2}$. Alginate-PLGA microcapsules were produced by this method, dried by fluid-bed drying and their structure observed using SEM (Figure 5). The SEM observation of fluid-bed dried alginate/PLGA multiparticulates revealed that the outer surface appeared to be highly occupied by PLGA particles. The internal structure was dense and showed clear evidence of PLGA microcapsules present within the matrix. It was also observed that the product was of a greater sphericity than the alginate microcapsules produced in a previous publication (Cook et al., 2011). This was most likely due to the PLGA microcapsules acting as a 'filler' in a similar manner to starch, reported widely in the literature (Chan et al.). 


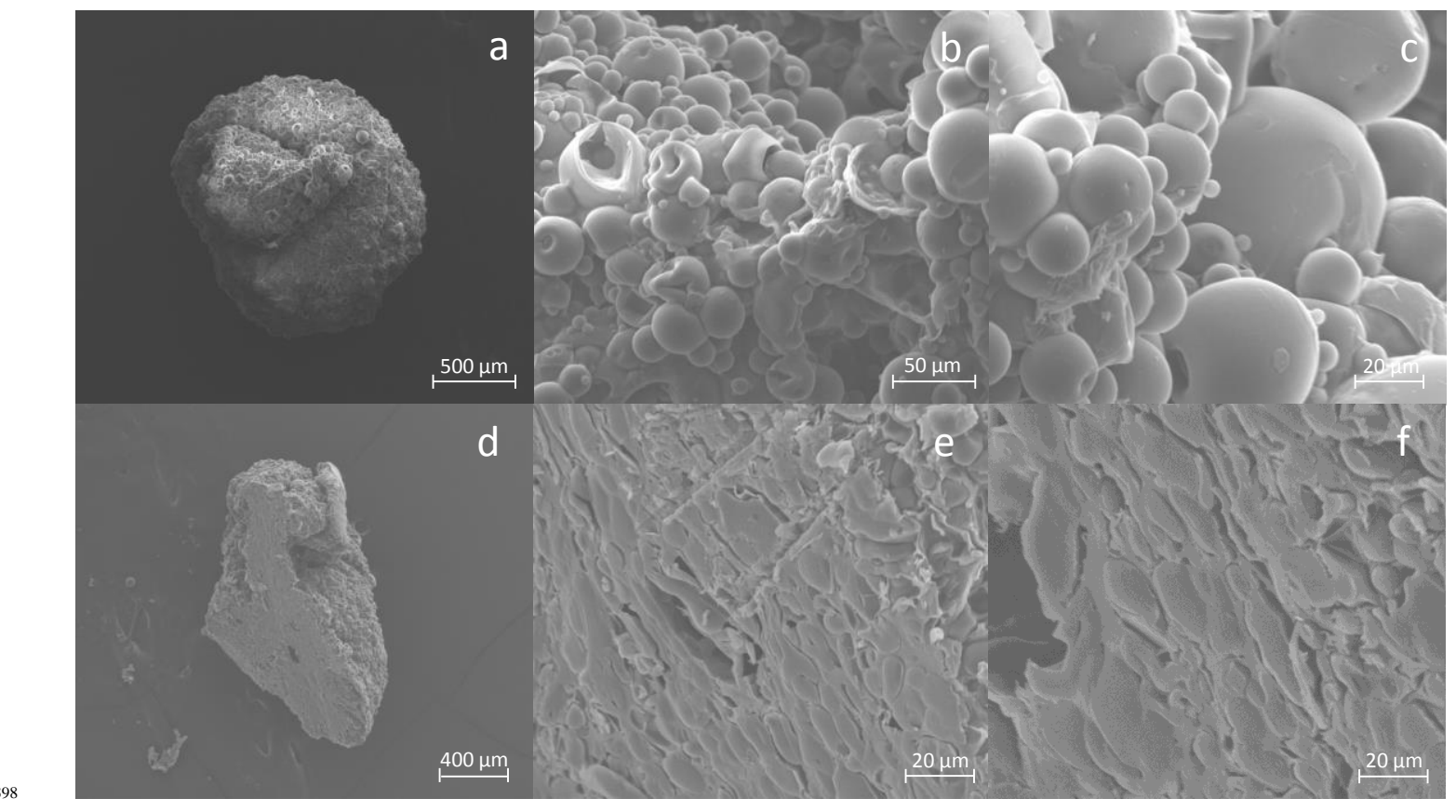

Figure 5: Fluid-bed dried alginate/PLGA multiparticulates observed using SEM. The external surface is shown at $50 x(a), 500 x(b)$ and $1000 x$ (c) magnification. The internal structure is then shown at 50x (d), 500x (e) and 1000x (f) magnification

In order to establish the release profile of GOS from the alginate/PLGA multiparticulates, the same in vitro method was used as for the PLGA particles alone. However, the purification process used previously was not applicable to solutions containing alginate as the polysaccharide is incompatible with the required eluent. A new method of purification was established, and it was found that the addition of a stoichiometric amount of calcium chloride led to the cross-linking of alginate and formation of an insoluble calcium phosphate. Both of these contaminants could be removed from solution by microfiltration. The formation of insoluble calcium phosphate was $\mathrm{pH}$ dependent; all samples were adjusted to $\mathrm{pH} 7.0$ with a known volume of $1 \mathrm{M} \mathrm{NaOH}$, so that the final data could be adjusted to take this volume change, and the volume of calcium chloride added, into account. This method led to a recovery of $95.3 \pm 1.7 \%$ of GOS when a solution of $2 \mathrm{mg} / \mathrm{mL} \mathrm{BiMuno}^{\mathrm{TM}}$ in simulated intestinal solution ( $\mathrm{pH} 7.0)$ with $1 \%$ alginate added was purified. 
To establish the effect of the polysaccharides alone, alginate and alginate-chitosan microcapsules were loaded with GOS and fluid-bed dried before being put through the simulated GI passage. The rate of GOS release with time was established using the previously described method of purification (Fig. 3s, Supplementary Information). The data shown allows two conclusions to be drawn; the encapsulation efficiency (i.e. the percentage of GOS added to the emulsion that was present in the final product) of GOS is very low and there was only a small control of release. This means that alginate and alginate-chitosan could not be used individually to deliver GOS in large amounts. The low encapsulation efficiency is understandable due to the length of time these materials are left to harden in calcium chloride, during which there will be diffusion of GOS from the matrix. As the cross-linking density of the alginate matrix increases with time, the diffusion of GOS out of the alginate would be most pronounced during the early stages of gelation, when the 'porosity' of the material is very high due to the low cross-linking density. Comparison of alginate and alginatechitosan does not yield any apparent differences in the rate of release of GOS, but it does appear that GOS loading into alginate microcapsules is higher, which would be a result of further diffusion of GOS out of the particles during the chitosan coating process. It should be noted, however, that the errors associated with the data make comparison of alginate to alginate-chitosan difficult. The encapsulation efficiencies were calculated, using the final reading of this experiment as the materials had completely dissolved, as $0.7 \pm 0.2 \%$ and $0.5 \pm$ $0.2 \%$ for alginate and alginate-chitosan, respectively.

GOS/PLGA multiparticulates were put through the in vitro GI model previously described and GOS release evaluated using the new purification method. The results in Figure 6 show that the level of release of GOS was not greatly affected by further encapsulation into alginate or alginate-chitosan, but there did appear to be a slight delay of release. In the case of the alginate-chitosan system the apparent change in release profile was greater, with some 
release appearing to occur between $12-24 \mathrm{~h}$, but the change was within error so conclusions are difficult to be drawn. Another, slightly unusual advantage of encapsulating the PLGA microcapsules was also observed. Prior to alginate encapsulation the PLGA microcapsules floated in solution, as seen in the in vitro studies for the PLGA capsules alone. The microcapsules would float for several hours before sinking, presumably due to sufficient water uptake. After encapsulation, the formulation would sink, and by dissolution of the alginate the PLGA microcapsules had apparently taken up sufficient water to not float. Whilst this seems initially trivial, in vivo this would result in the retention of the formulation in the stomach, as is the intention of floating delivery devices (Kawashima et al., 1992), so that the PLGA microcapsules would release a larger fraction of their load into the stomach.

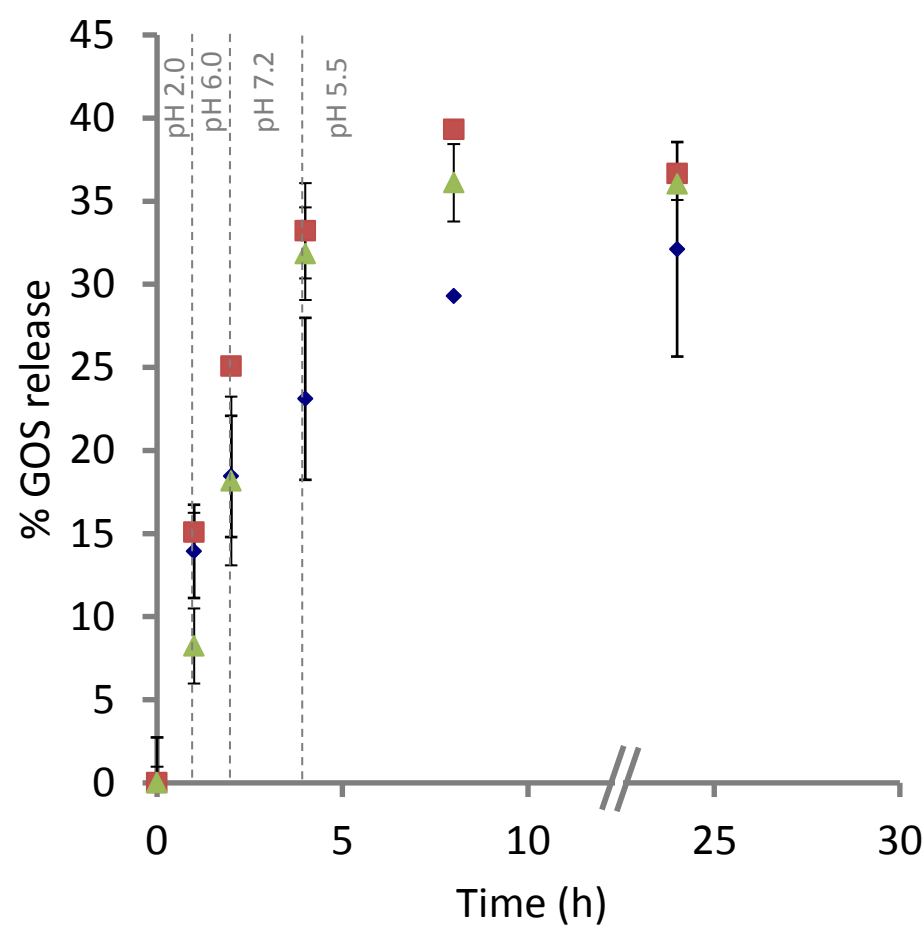

Figure 6: Release of GOS from PLGA/alginate (blue diamonds) and PLGA/alginate-chitosan (red-squares) multiparticulates during simulated GI passage. The release of GOS from PLGA microcapsules containing $1 \mathrm{~mL}$ internal phase overlaid (green triangles). Data given as mean \pm standard deviation $(n=3)$. 

of the alginate microcapsules to protect the cells, B. breve was included into the multiparticulate alginate matrices in which the GOS/PLGA microcapsules were also incorporated. These microcapsules were coated with chitosan in order to evaluate the effect of coating on these materials. Coating with chitosan has previously shown efficacy in improving protection from gastric acid (Doherty et al., 2012a). This system was then run through the simulated GI passage described previously, with cell counts taken from solution. This should give an idea of both the number of cells surviving in gastric solution, and the rate of release of cells from these materials. Results displayed in Figure 7, show higher cell numbers surviving in the chitosan coated multiparticulate system relative to that predicted by cell survival after encapsulation in chitosan-coated alginate microcapsules without GOS/PLGA. It has been found that after encapsulation in alginate-chitosan and fluid-bed drying, $6.6 \pm 0.5$ $\log$ CFU/mL cells of $B$.breve survived $1 \mathrm{~h}$ in simulated gastric solution (Cook et al., 2011). The data in Figure 7 suggests that up to $8.0 \pm 0.3 \log$ CFU/mL cells survived when GOS/PLGA was included into the formulation, which was statistically different by T-testing $(p<0.001)$. Without encapsulation, it is known that B.breve survives for less than $1 \mathrm{~h}$ in gastric solution (Cook et al., 2011). One possible explanation for the increase in the number viable cells found after exposure to gastric conditions could be the large number of hydrophobic PLGA microcapsules found on the surface of the alginate matrix. This could act as a hydrophobic coat, reducing the water-permeability of the capsules. The particles on the surface could also simply reduce the surface area of the permeable alginate capsules, thereby slowing the rate of acid diffusion into the matrix. It is also possible that there is some influence from the encapsulated GOS, stimulating the growth of cells, but this was thought less likely due to the absence of other nutrients needed to start cell division. 


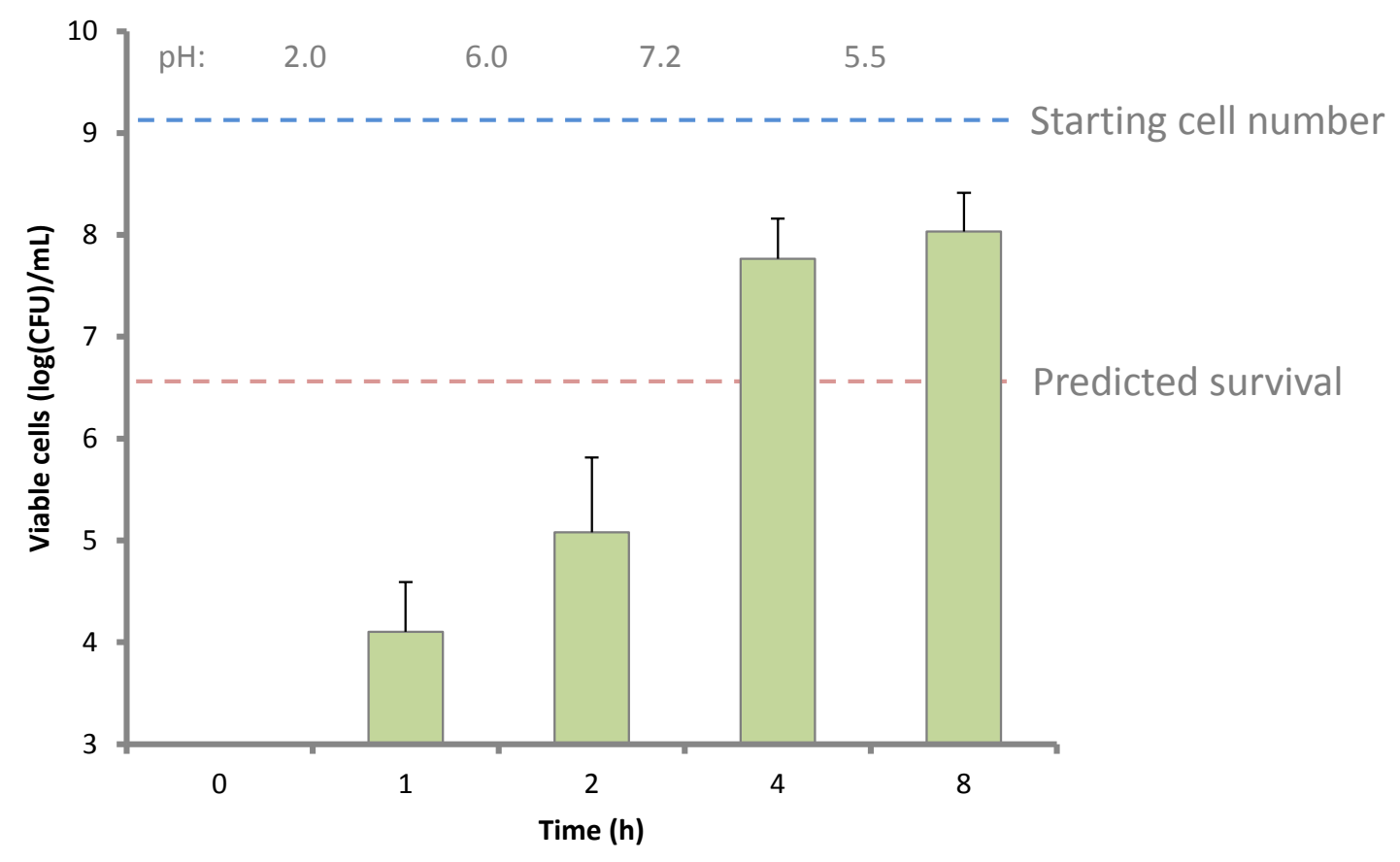

Figure 7: Release of viable $B$. breve from PLGA/alginate multiparticulates with a single layer of chitosan in simulated GI conditions, relative to the survival predicted by chitosan-coated alginate microcapsules. Survival is predicted based on alginate-chitosan systems without PLGA/GOS microcapsules incorporated. Limit of detection: $3 \log (\mathrm{CFU}) / \mathrm{mL}$. Data given as mean and standard deviation $(n=3)$. Please note that the $x$-axis is not linear.

\subsection{Concluding remarks}

GOS was successfully encapsulated into hollow PLGA microcapsules. These microcapsules

were able to control the release of GOS, giving a triphasic release profile during in vitro GI conditions in which around $25 \%$ of the GOS initially added was released over $6 \mathrm{~h}$. In vivo this timescale should correlate approximately to gastric transit, small intestinal transit and early large intestinal transit. The porosity of these microcapsules could be varied by altering the internal phase volume of the microcapsules, but did not affect the rate of release to the 
degree needed to move to a single-phasic release profile. From the volumes used, the largest quantity of GOS delivered in the first phase of release was $36 \%$, achieved with $1 \mathrm{~mL}$ internal phase volume. It is possible that in future the release and drug loading of these particles could be optimised by further examination of the processing parameters and PLGA/GOS concentrations. The incorporation of GOS/PLGA microcapsules into alginate and chitosancoated alginate microcapsules gave similar results to the GOS/PLGA microcapsules alone, with a small extension of release seen in the chitosan coated capsules. Incorporation into alginate systems halted the floatation of the formulation, which would alter the distribution of the GOS in vivo. Expanding this system to also include $B$. breve resulted in a higher survival of cells when exposed to simulated gastric solution, which is believed to be, in part, due to the increased hydrophobicity of the materials after the incorporation of PLGA microcapsules. 


\subsection{Acknowledgements}

Clasado Ltd are thanked for funding this project and providing BiMuno ${ }^{\mathrm{TM}}$.

\subsection{References}

Borza, A.D., Annan, N.T., Moreau, D.L., Allan-Wojtas, P.M., Ghanem, A., Rousseau, D., Paulson, A.T., Hansen, L.T., 2010. Microencapsulation in genipin cross-linked gelatine-maltodextrin improves survival of Bifidobacterium adolescentis during exposure to in vitro gastrointestinal conditions. J. Microencapsulation 27, 387-399.

Chan, E.-S., Wong, S.-L., Lee, P.-P., Lee, J.-S., Ti, T.B., Zhang, Z., Poncelet, D., Ravindra, P., Phan, S.-H., Yim, Z.-H., Effects of starch filler on the physical properties of lyophilized calciumalginate beads and the viability of encapsulated cells. Carbohydr. Polym. 83, 225-232.

Chandramouli, V., Kailasapathy, K., Peiris, P., Jones, M., 2004. An improved method of microencapsulation and its evaluation to protect Lactobacillus spp. in simulated gastric conditions. J. Microbiol. Meth. 56, 27-35.

Chavarri, M., Maranon, I., Ares, R., Ibanez, F.C., Marzo, F., Villaran Mdel, C., 2010. Microencapsulation of a probiotic and prebiotic in alginate-chitosan capsules improves survival in simulated gastro-intestinal conditions. Int. J. Food Microbiol. 142, 185-189.

Cohen, S., Yoshioka, T., Lucarelli, M., Hwang, L.H., Langer, R., 1991. Controlled delivery systems for proteins based on poly(lactic/glycolic acid) microspheres. Pharm. Res. 8, 713-720.

Cook, M.T., Tzortzis, G., Charalampopoulos, D., Khutoryanskiy, V.V., 2011. Production and evaluation of dry alginate-chitosan microcapsules as an enteric delivery vehicle for probiotic bacteria. Biomacromolecules 12, 2834-2840.

Cook, M.T., Tzortzis, G., Charalampopoulos, D., Khutoryanskiy, V.V., 2012. Microencapsulation of probiotics for gastrointestinal delivery. J. Control. Release 162, 56-67.

Cook, M.T., Tzortzis, G., Khutoryanskiy, V.V., Charalampopoulos, D., 2013. Layer-by-layer coating of alginate matrices with chitosan-alginate for the improved survival and targeted delivery of probiotic bacteria after oral administration. J. Mater. Chem. B 1, 52-60.

Corrigan, O.I., Li, X., 2009. Quantifying drug release from PLGA nanoparticulates. Eur. J. Pharm. Sci. 37, 477-485.

Cui, J.H., Cao, Q.R., Lee, B.J., 2007. Enhanced delivery of bifidobacteria and fecal changes after multiple oral administrations of bifidobacteria-loaded alginate poly-I-lysine microparticles in human volunteers. Drug Deliv. 14, 265-271. 
Ding, W.K., Shah, N.P., 2009. Effect of various encapsulating materials on the stability of probiotic bacteria. J. Food Sci. 74, M100-M107.

Doherty, S., Auty, M., Stanton, C., Ross, R., Fitzgerald, G., Brodkorb, A., 2012a. Application of whey protein micro-bead coatings for enhanced strength and probiotic protection during fruit juice storage and gastric incubation. J. Microencapsulation.

Doherty, S.B., Auty, M.A., Stanton, C., Ross, R.P., Fitzgerald, G.F., Brodkorb, A., 2012b. Survival of entrapped Lactobacillus rhamnosus GG in whey protein micro-beads during simulated ex vivo gastro-intestinal transit. Int. Dairy J. 22, 31-43.

El-Sherbiny, I.M., Abdel-Mogib, M., Dawidar, A.-A.M., Elsayed, A., Smyth, H.D.C., 2011. Biodegradable $\mathrm{pH}$-responsive alginate-poly (lactic-co-glycolic acid) nano/micro hydrogel matrices for oral delivery of silymarin. Carbohydr. Polym. 83, 1345-1354.

Fuller, R., 1991. Probiotics in Human Medicine. Gut 32, 439-442.

Gibson, G.R., Probert, H.M., Loo, J.V., Rastall, R.A., Roberfroid, M.B., 2004. Dietary modulation of the human colonic microbiota: updating the concept of prebiotics. Nutr. Res. Rev. 17, 259275.

Gibson, G.R., Roberfroid, M.B., 1995. Dietary Modulation of the Human Colonic Microbiota Introducing the Concept of Prebiotics. J. Nutr. 125, 1401-1412.

Graff, S., Hussain, S., Chaumeil, J.C., Charrueaul, C., 2008. Increased intestinal delivery of viable Saccharomyces boulardii by encapsulation in microspheres. Pharm. Res. 25, 1290-1296.

Heidebach, T., Forst, P., Kulozik, U., 2009. Transglutaminase-induced caseinate gelation for the microencapsulation of probiotic cells. Int. Dairy J. 19, 77-84.

Herrmann, J., Bodmeier, R., 1995. Somatostatin containing biodegradable microspheres prepared by a modified solvent evaporation method based on W/O/W-multiple emulsions. Int. J. Pharm. 126, 129-138.

Homayouni, A., Azizi, A., Ehsani, M.R., Yarmand, M.S., Razavi, S.H., 2008. Effect of microencapsulation and resistant starch on the probiotic survival and sensory properties of synbiotic ice cream. Food Chem. 111, 50-55.

Kawashima, Y., Niwa, T., Takeuchi, H., Hino, T., Itoh, Y., 1992. Hollow microspheres for use as a floating controlled drug delivery system in the stomach. J. Pharm. Sci. 81, 135-140.

Klose, D., Siepmann, F., Elkharraz, K., Krenzlin, S., Siepmann, J., 2006. How porosity and size affect the drug release mechanisms from PLGA-based microparticles. Int. J. Pharm. 314, 198206.

Krishnamachari, Y., Madan, P., Lin, S., 2007. Development of pH-and time-dependent oral microparticles to optimize budesonide delivery to ileum and colon. Int. J. Pharm. 338, 238-247. 
Lamprecht, A., Yamamoto, H., Takeuchi, H., Kawashima, Y., 2004. Design of pH-sensitive microspheres for the colonic delivery of the immunosuppressive drug tacrolimus. Eur. J. Pharm. Biopharm. 58, 37-43.

Li, X.Y., Chen, X.G., Cha, D.S., Park, H.J., Liu, C.S., 2009. Microencapsulation of a probiotic bacteria with alginate-gelatin and its properties. J. Microencapsulation 26, 315-324.

Liserre, A.M., Re, M.I., Franco, B., 2007. Microencapsulation of Bifidobacterium animalis subsp lactis in modified alginate-chitosan beads and evaluation of survival in simulated gastrointestinal conditions. Food Biotechnol. 21, 1-16.

Mahboubian, A., Hashemein, S.K., Moghadam, S., Atyabi, F., Dinarvand, R., 2010. Preparation and In-vitro Evaluation of Controlled Release PLGA Microparticles Containing Triptoreline. Iran. J. Pharm. Res. 9, 369-378.

Mao, S., Xu, J., Cai, C., Germershaus, O., Shaper, A., Kissel, T., 2007. Effect of WOW process parameters on morphology and burst release of FITC-dextran loaded PLGA microsphere. Int. J. Pharm. 334, 137-148.

Mokarram, R.R., Mortazavi, S.A., Najafi, M.B.H., Shahidi, F., 2009. The influence of multi stage alginate coating on survivability of potential probiotic bacteria in simulated gastric and intestinal juice. Food Res. Int. 42, 1040-1045.

Muthukumarasamy, P., Allan-Wojtas, P., Holley, R.A., 2006. Stability of Lactobacillus reuteri in different types of microcapsules. J. Food Sci. 71, M20-M24.

Ng, S.C., Hart, A.L., Kamm, M.A., Stagg, A.J., Knight, S.C., 2009. Mechanisms of action of probiotics: recent advances. Inflamm. Bowel Dis. 15, 300-310.

Oliveira, A.C., Moretti, T.S., Boschini, C., Baliero, J.C.C., Freitas, O., Favaro-Trindade, C.S., 2007. Stability of microencapsulated B. lactis (BI 01) and L. acidophilus (LAC 4) by complex coacervation followed by spray drying. J. Microencapsulation 24, 673-681.

Rembacken, B.J., Snelling, A.M., Hawkey, P.M., Chalmers, D.M., Axon, A.T.R., 1999. Nonpathogenic Escherichia coli versus mesalazine for the treatment of ulcerative colitis: a randomised trial. Lancet 354, 635-639.

Schlicher, E.J.A.M., Postma, N.S., Zuidema, J., Talsma, H., Hennink, W.E., 1997. Preparation and characterisation of Poly (d,I-lactic-co-glycolic acid) microspheres containing desferrioxamine. Int. J. Pharm. 153, 235-245.

Schmidt, C., Lautenschlaeger, C., Collnot, E.M., Schumann, M., Bojarski, C., Schulzke, J.D., Lehr, C.M., Stallmach, A., 2013. Nano- and microscaled particles for drug targeting to inflamed intestinal mucosa: a first in vivo study in human patients. J. Control. Release 165, 139-145.

Searle, L.E., Best, A., Nunez, A., Salguero, F.J., Johnson, L., Weyer, U., Dugdale, A.H., Cooley, W.A., Carter, B., Jones, G., Tzortzis, G., Woodward, M.J., La Ragione, R.M., 2009. A mixture containing galactooligosaccharide, produced by the enzymic activity of Bifidobacterium 
bifidum, reduces Salmonella enterica serovar Typhimurium infection in mice. J. Med.

Microbiol. 58, 37-48.

Searle, L.E.J., Jones, G., Tzortzis, G., Woodward, M.J., Rastall, R.A., Gibson, G.R., La Ragione, R.M., 2012. Low molecular weight fractions of BiMuno ${ }^{\circledR}$ exert immunostimulatory properties in murine macrophages. Journal of Functional Foods 4, 941-953.

Sturesson, C., Carlfors, J., Edsman, K., Andersson, M., 1993. Preparation of biodegradable poly(lactic-co-glycolic) acid microspheres and their in vitro release of timolol maleate. Int. J. Pharm. 89, 235-244.

Sultana, K., Godward, G., Reynolds, N., Arumugaswamy, R., Peiris, P., Kailasapathy, K., 2000. Encapsulation of probiotic bacteria with alginate-starch and evaluation of survival in simulated gastrointestinal conditions and in yoghurt. Int. J. Food Microbiol. 62, 47-55.

Tzortzis, G., Goulas, A.K., Gee, J.M., Gibson, G.R., 2005. A novel galactooligosaccharide mixture increases the bifidobacterial population numbers in a continuous in vitro fermentation system and in the proximal colonic contents of pigs in vivo. J. Nutr. 135, 1726-1731.

Wischke, C., Schwendeman, S.P., 2008. Principles of encapsulating hydrophobic drugs in PLA/PLGA microparticles. Int. J. Pharm. 364, 298-327.

Wright, B., Cave, R.A., Cook, J.P., Khutoryanskiy, V.V., Mi, S., Chen, B., Leyland, M., Connon, C.J., 2012. Enhanced viability of corneal epithelial cells for efficient transport/storage using a structurally modified calcium alginate hydrogel. Regen. Med. 7, 295-307. 
Figure 1s. GOS separation using ion-exchange chromatography. Peaks, from left to right:

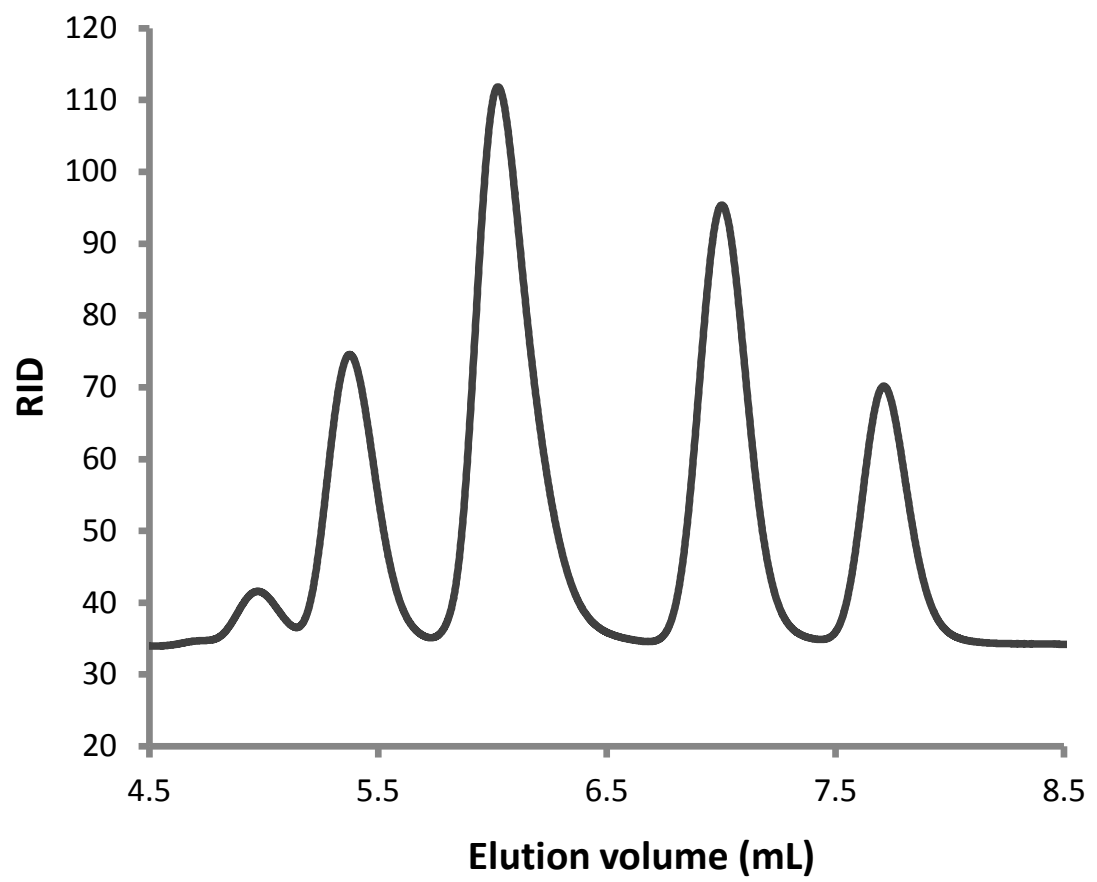

Figure 2s.In vitro GI passage used in GOS release studies

\begin{tabular}{|l|l|l|}
\hline Region simulated & pH & Exposure time (h) \\
\hline Stomach & 2.0 & $0-1$ \\
\hline Proximal small intestine & 6.0 & $1-2$ \\
\hline Distal small intestine & 7.2 & $2-4$ \\
\hline Large intestine & 5.5 & 4 onwards \\
\hline
\end{tabular}


${ }_{643}$ Figure 3s. Release of GOS from alginate and alginate-chitosan capsules

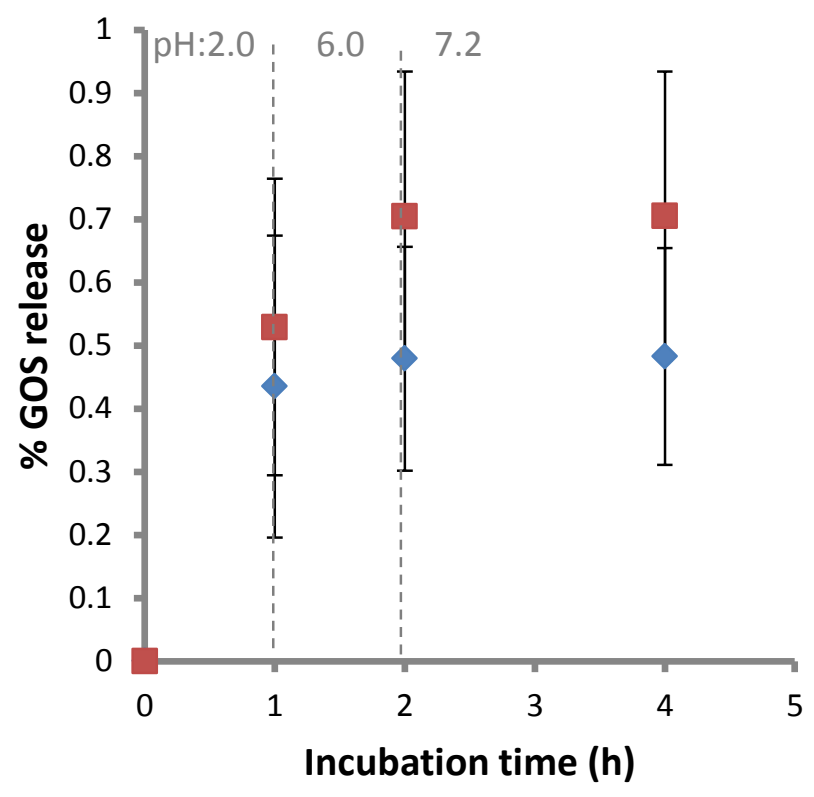

644 